\title{
Focal therapy, time to join the multi-disciplinary team discussion?
}

\author{
Deepika Reddy ${ }^{1}$, Nishant Bedi ${ }^{2}$, Tim Dudderidge ${ }^{3}$ \\ ${ }^{1}$ Imperial Prostate, Division of Surgery, Department of Surgery and Cancer, Imperial College London, London, UK; ${ }^{2}$ Imperial Urology, Charing \\ Cross Hospital, Imperial College Healthcare NHS Trust, London, UK; ${ }^{3}$ Department of Urology, Southampton General Hospital, University \\ Hospital Southampton NHS Trust, Southampton, UK \\ Contributions: (I) Conception and design: D Reddy, T Dudderidge; (II) Administrative support: All authors; (III) Provision of study materials or \\ patients: D Reddy, N Bedi; (IV) Collection and assembly of data: D Reddy, N Bedi; (V) Data analysis and interpretation: D Reddy, T Dudderidge; \\ (VI) Manuscript writing: All authors; (VII) Final approval of manuscript: All authors. \\ Correspondence to: Deepika Reddy. Imperial Prostate, Division of Surgery, Department of Surgery and Cancer, Imperial College London, London, \\ UK. Email: deepika.reddy06@imperial.ac.uk.
}

\begin{abstract}
Organ preserving management is common place in renal cancer, breast cancer and many other solid organ tumours. Current strategies in managing intermediate risk prostate cancer include either whole gland treatment, in the form of radical radiotherapy or radical prostatectomy, or active surveillance. The former is associated with significant post-treatment functional morbidity, whilst the latter associated with the burden of surveillance activity and patient anxiety. Focal therapy would logically fit as a middle ground for suitable patients in whom treatment would be recommended, but where much better functional outcomes may be possible. Ideally this comes without restricting the successful prevention of harm from the cancer. Historically limitations in developing tissue preserving focal therapy strategies in prostate cancer, were due to inaccuracies in tumour characterisation prior to treatment and during follow up. Consequently for example many patients undergoing an active surveillance strategy were being upgraded and upstaged within a short period. Recently high level evidence supporting the use of MRI and targeted biopsies, in particular the PROMIS and PRECISION trials have strengthened clinician confidence in accurate disease characterisation, thus making focal therapy to become a more feasible management option. With improved diagnostic strategies and the publication of reassuring medium term oncological and functional outcomes after focal therapy for intermediate risk prostate cancer, has the time come to require consideration of focal therapy within our multi-disciplinary team (MDT) meetings and with patients? In this review we will consider patient selection and the evidence for the various focal ablation options as well as the surveillance of these patients after treatment. The forthcoming trials to determine comparative effectiveness will be discussed.
\end{abstract}

Keywords: Focal ablative prostate treatment; prostate cancer; high intensity focused ultrasound ablation; cryotherapy; photodynamic therapy; laser therapy

Submitted Aug 23, 2019. Accepted for publication Sep 20, 2019.

doi: $10.21037 /$ tau.2019.09.30

View this article at: http://dx.doi.org/10.21037/tau.2019.09.30

\section{Introduction}

It is widely understood by patients, general practitioners and specialists that prostate cancer is a heterogeneous disease with a spectrum of risk to patients ranging from no symptoms during life, to developing symptomatic metastatic disease needing systemic therapies or indeed death. It is also understood, that considering this variance, a range of treatment approaches for localised disease are needed. These range from active surveillance for low risk disease, to radical therapy for disease that although localised, appears to present a high risk of progression or death if the patient is not treated. Focal ablation has emerged in the last 10 years as a middle ground where treatment and eradication of disease is possible but without the burden of side effects and complications seen with whole gland 
therapies.

In this review we aim to present the background data supporting whole gland therapy and its proposed advantages over surveillance/conservative management. The risks of these treatments will be discussed to demonstrate the tradeoff being made by men who choose this approach.

We will discuss the selection of men potentially suitable for focal therapy, who make up approximately $40 \%$ of men currently treated for prostate cancer (1). We will present the different focal treatment modalities and discuss the evidence for these treatments including the functional results.

We will end by discussing the other trade offs that some men prefer to make, choosing reduced side effects with focal therapy despite the absence of comparative and longterm data for these treatments. We will also highlight proposed and ongoing trials seeking to provide randomised comparative data with long term follow up that may one day provide evidence of equivalence in cancer outcome in suitable men.

\section{The rationale and outcomes for radical treatment}

In reviewing the PIVOT study, a clinician can have confidence that not all prostate cancer demands treatment. Those with low risk disease may have no progression or survival benefit after radical therapies in comparison to observation alone $(2,3)$. Whilst the ProtecT study demonstrated no overall survival benefit, metastatic progression was less likely in patients undergoing radical treatments for localised prostate cancer in comparison to active surveillance (4).

These large robust studies have led to a more targeted use of radical treatments for localised intermediate and high-risk prostate cancer. Even so, the use of radical therapy and its inherent functional consequences, still may represent over treatment for many men and less harmful treatments may represent a better balance of benefit and risk for some.

\section{Rationale for focal therapy}

Focal therapy is not an alternative to active surveillance but may lend itself to a group of patients with clinically significant, localized targetable disease who value their genitourinary function (5).

There has been a significant movement towards tissue sparing treatments over the last 25 years, notably the move from radical mastectomy as the standard, to wide local excision for many patients nowadays (6). Oncological outcomes are demonstrated to be excellent, with markedly reduced morbidity. Similarly, small renal tumours are increasingly managed with tissue preserving techniques using percutaneous or laparoscopic cryotherapy, resulting in comparable oncological control, fewer complications, and minimised renal dysfunction (7).

Uptake of tissue sparing techniques has been hindered within the prostate cancer field, due to the historic difficulty in accurately localising the regions of the gland affected by the disease (8). For example, active surveillance patients diagnosed by TRUS biopsy have demonstrated early upstaging/upgrading in 26-40\% of men that underwent subsequent combination of template and MRI-targeted biopsy, or template mapping biopsy alone $(9,10)$.

Diagnostic modalities are improving rapidly, leading to focal therapy becoming increasingly accepted. Currently NICE guidance IPG 424/2 and IPG 423/2 allow for the use of high intensity focused ultrasound (HIFU) or cryotherapy provided prospective data is collected, and further focal therapies are permissible within trial settings.

\section{Suitable diagnostic pathways and patient selection for focal therapy}

High diagnostic accuracy and precise disease localization to appropriately risk-stratify patients are vitally important to understand which patients would benefit from active surveillance strategies, compared to those that could benefit from curative strategies (3). With the use of prebiopsy mpMRI and mpMRI guided biopsies, clinicians can be increasingly confident in the accuracy of diagnosis and identification of the index lesion (11-13). Targeting index lesions identified with mpMRI using ablation confers good oncological control in the early setting, whilst minimizing post-procedure morbidity (14). Focal therapy may also be appropriate in patients demonstrating multifocal disease, provided contralateral untreated tumours are of grade and volume appropriate for surveillance (15). Using MRI guided biopsies, clinicians can accurately characterise suspicious lesions to more precisely guide the treatment area during focal therapy sessions (16). However, limiting margins may be a counterproductive measure, as MRI may not clearly define the extent of disease, and it is now recommended to ablate with at least a $9 \mathrm{~mm}$ margin around an imaging target (17). This requirement may limit the benefits of a focal approach in cases where avoidance of nerve bundles/sphincter can't be avoided on at least one side. 


\section{The evidence for focal therapy}

There is minimal level 1 evidence comparing focal ablative therapies to established radical therapies in low and intermediate risk disease, and thus clinicians mainly are reliant upon cohort, case matching studies and phase II/III studies comparing against active surveillance $(11-14,18,19)$. A review of multiple focal ablative techniques by McClure et al. demonstrated acceptable short-term outcomes. The authors highlighted the need for longterm oncological follow up and randomised control trials in order to determine the efficacy of focal therapy (20). Table 1 identifies studies reviewing focal therapy for prostate cancer with results and registered to clinicaltrials.gov.

\section{HIFU}

Focal HIFU involves the thermal destruction of a selected region of the prostate using a device that images and treats sequentially with the option of MRI fusion guided treatment. Currently there are 3 devices approved for HIFU delivery: SonaCare ${ }^{\mathrm{TM}}$, Ablatherm ${ }^{\mathrm{TM}}$, and FocalOne ${ }^{\mathrm{TM}}$, which have considerable technological differences. All three devices have demonstrated good early cancer control, along with excellent functional outcomes, the results appear to be dependent upon ablation strategy rather than device used (21).

An observational study of 75 men reported recurrence of clinically significant prostate cancer at 6 months post HIFU in $41 \%$ of patients, with high post-procedure functional outcomes (22). A prospective UK registry study of 625 men treated using the sonablate device revealed a failure free survival of $88 \%$ at 5 years, with overall survival of $99 \%$ and only $7 \%$ requiring salvage radical therapy (23). A propensity matched study reviewing 55 patients that underwent hemiablation with HIFU or RARP demonstrated no statistical difference in rates of transition to salvage therapy, whilst rates of de novo erectile dysfunction was significantly lower in the HIFU group after 3 years, whilst pad free urinary continence was significantly better (24). The INDEX study has recruited 511 patients at multiple centres with low to intermediate risk unilateral disease. This study has more rigid protocol biopsies than the registry and medium-term outcomes of the initial cohort of 140 patients are due to be published shortly (25).

\section{Cryotherapy}

Cryotherapy destroys tissue using argon gas passed through needles which leads to the formation of varied sized ice balls depending on the needle selected. Used in combination the activated needles destroy the selected region of prostate whilst preserving the sphincter, nerves, rectum and normal parts of the gland. Further techniques such as urethral warmers via catheterization and thermocouples can improve preservation of neurovascular bundles and sphincter function (26).

Focal cryotherapy appears to be an effective treatment for primary localized prostate cancer and compares favourably to radical/whole gland treatments in mediumterm oncological outcomes and side-effects. A feasibility study by Valerio et al. demonstrated that MRI-TRUS fusion guided cryotherapy is feasible, safe and appears to result in good functional outcomes (27). The importance of being able to safely and accurately use fusion techniques allow movement away from in-bore modalities, resulting in more accessible and cost-effective cryotherapy options. Subsequent studies have strengthened the support for using cryotherapy for localized disease. Further 3 -year outcomes after cryotherapy include FFS of $90.5 \%$ with no significant difference when stratifying against high or intermediate risk groups (28).

\section{Photodynamic therapy (PDT)}

PDT requires the use and activation of a vascular photosensitizer using a laser. The most common photosensitizer evaluated is padeliporfin $\left(\right.$ TOOKAD $\left.^{\circledR}\right)$ and provides the highest level of evidence for all focal therapy modalities.

Having undergone a level III RCT in low risk prostate cancer compared to active surveillance, PDT results in good functional outcomes post procedure, however it demonstrated a high rate of progression (18). Currently PDT is not recommended in standard practice in the $\mathrm{UK}$, due to the lack of comparative data against radical treatments in patients with intermediate risk prostate cancer, whilst still being associated with long-term side effects (NICE guidance TA546).

\section{Irreversible electroporation (IRE)}

IRE utilises non-thermal tissue destruction through its targeted disruption of cell membranes via two or more electrodes. IRE encompasses the use of electrical energy delivered into specific areas of prostatic tissue via specialized needles directed through the perineum (26). The ability 


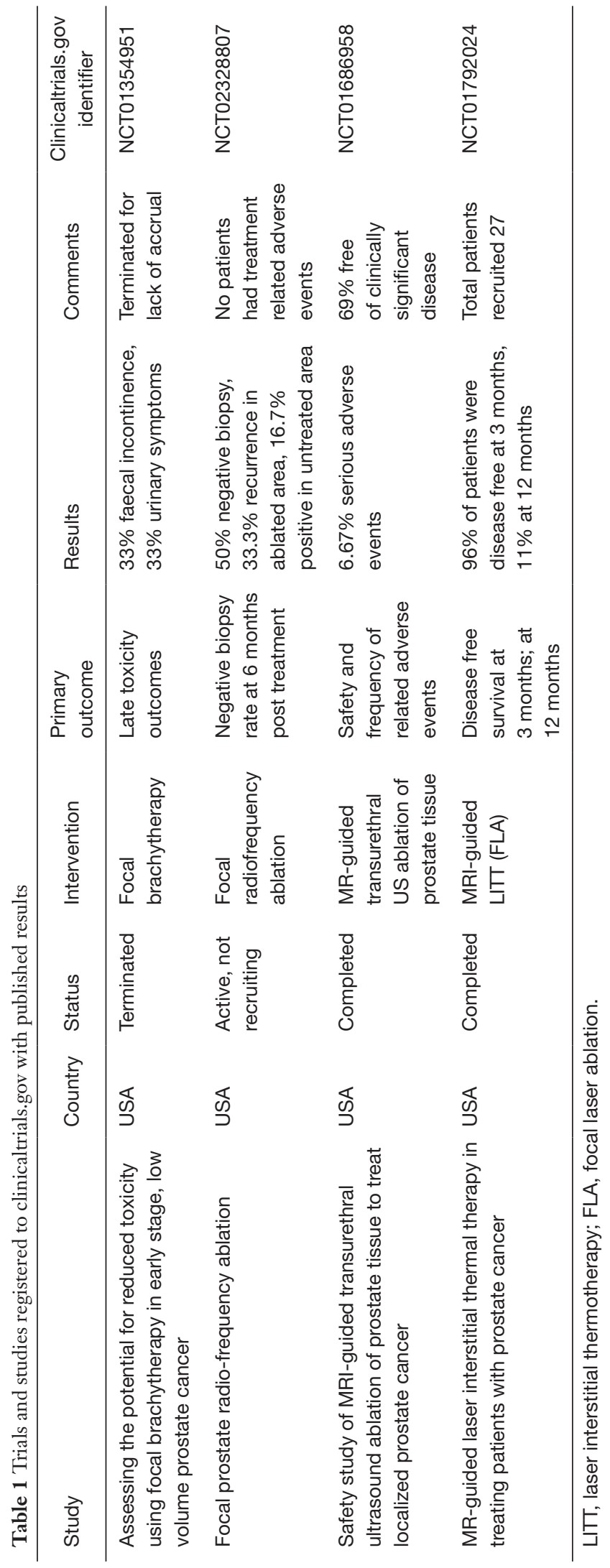

to determine which area of tissue has reached the electric threshold to induce irreversible electroporation allows for more accurate tissue sparing compared to cryotherapy and HIFU (29). Despite accuracy of targeting tissue, IRE often requires repeat treatment to allow for adequate oncological control (30). van den Bos et al. recommended the use of $10 \mathrm{~mm}$ margins to optimize oncological control, compared to $6 \mathrm{~mm}$ margins after initial analysis demonstrating an increase of in-field oncological control at 6 months from $84 \%$ to $97 \%$ (31).

A propensity matched study, by Scheltema et al., reviewed early outcomes of IRE against RARP, demonstrating significantly better conservation of pad-free urinary continence and erectile function. However oncological failure at 12 months was worse in the IRE group, with $70.5 \%$ of patients meeting the study's definition of failure free survival compared to $100 \%$ of patients 12 months after RARP (32). Worse oncological control in the IRE group may be at least in part explained by the inclusion of patients during the initial learning curve, whilst RARP procedures occurred after completion of the learning curve.

A small phase I/II trial reviewing the histopathological changes induced by IRE demonstrated early efficacy in post-treatment prostatectomy is underway and results are pending (33). A larger phase I/II trial (NCT01835977) aiming to recruit 200 patients in order to evaluate focal $v s$. extended ablation via IRE is underway, and due to provide outcomes over 5 years (34).

Currently, despite promising early data, the lack of comparative medium-long term data has limited its uptake into practice (35).

\section{Focal laser ablation (FLA)}

FLA induces coagulation necrosis using either $1,064 \mathrm{~nm}$ Nd:YAG lasers, 830 or $980 \mathrm{~nm}$ diode lasers, and typically requires $\mathrm{MRI} /$ real time image guidance. Laser fibres are inserted via the perineum, and the focused electromagnetic energy causes thermal destruction of targeted tissues $(26,36,37)$. The use of FLA was documented over 10 years ago, in a small study evaluating the histopathological changes prior to prostatectomy. The group noted accurate homogenous coagulative necrosis in the treated area, and MRI was able to accurately locate the treated area. The study also demonstrated $2 / 3$ of patients demonstrating no disease in the treated area after 3-6 months. However, the authors have not published long term oncological or functional outcomes (38). Recurrence free survival 3 months 
after FLA has been reported as high as $96 \%$, with no patient reported incontinence or significant reduction in quality of life (39). A small prospective cohort study demonstrated disease free survival at 1 year to be $92 \%$, with no significant differences in pre- and post-treatment erectile and urinary patient reported outcomes in the short term. However long term oncological and functional outcomes are awaited (36). Similar results and conclusions were demonstrated within a systematic review by Valerio et al, supporting this modality as a safe procedure, though lacked long term follow-up (40).

Two further trials have been registered to clinicaltrials. gov, and results are pending publication (NCT01377753 and NCT01094665). Importantly in 2017, Natarajan et al. have demonstrated feasibility of performing FLA under MRI-ultrasound fusion, which would allow FLA to become a more practical focal therapy modality (37). The current major limitation is the lack of comparative and long-term data in men with intermediate risk disease.

\section{Radio-frequency ablation (RFA)}

RFA has been described in the role of prostate cancer treatment for over 20 years (41). RFA involves the use of either one monopolar needle, or two bipolar needles placed under TRUS guidance. Thermal energy is then used to ablate the surrounding areas, with accuracy improved using thermocouples. Although two trials (NCT02303054 and NCT01423006) have been registered to clinicaltrials.gov, no results have been published to this date. Oncological results after RFA are minimal in the literature, limiting the use of RFA in standard care in the near future.

\section{Brachytherapy}

Focal brachytherapy may be a useful technique in the future, however current literature mainly revolves around feasibility and very few studies report oncological outcomes $(42,43)$. Multiple studies have evaluated the use of targeted seed placement into the site of tumour and results suggest safety, with transient changes in quality of life (44). Like other focal therapy modalities, the lack of long term and comparative data continues to limit the uptake of focal brachytherapy into standard practice.

\section{UK National Institute of Clinical Evidence Guidelines}

Currently with the lack of high-level evidence, NICE guidelines (IPG 423/1, IPG 423/2, IPG 424/1 and IPG $424 / 2$ ) allow the use of focal therapy in the context of clinical trials, or with the use of prospective data collection when utilising HIFU or cryotherapy (40). However whole gland treatment or active surveillance remain standard of care outside of clinical trials (NG131).

\section{Ongoing trials and studies}

In the absence of widespread adoption for focal therapy as standard of care, patients must consider enrolment into phase II/III clinical studies. To date 12 studies have been registered in Europe to clinicaltrials.gov, 9 from North America, 3 from the Middle East and Asia and 1 from Australia; results of which are pending (Table S1).

\section{Monitoring after following treatment}

Following treatment, patients can be monitored through repeat imaging, serial PSA tests and repeat biopsies. A criticism of focal ablation is the inability to easily visualize treatment margins in real-time. A small study by Apfelbeck et al. explored the use of contrast enhanced ultrasound following HIFU, comparing it to MRI the pretreatment MRI, immediately and shortly after treatment. The initial findings were encouraging, and further study is needed to establish the role of contrast-enhanced ultrasound (CEUS) after ablation (45). Scheltema et al. are undergoing a phase I/II clinical trial evaluating IRE as a focal treatment modality, comparing the use of mpMRI and/or CEUS against transperineal template mapping biopsy, for follow up techniques, the results of which are pending (35).

Various groups have shown inconsistent results in using solitary follow-up modalities after focal therapy (46). No international consensus group has been able to determine a consistent definition for biochemical failure after focal therapy, concluding that multi-modal follow-up investigations are required to accurately diagnose patients with residual or recurrent disease in a timely manner. Consensus groups have assessed these studies and have not only determined an appropriate patient population to be approached for focal therapy but have also suggested follow-up and monitoring protocols (47-50). The combination of PSA, MRI and biopsy are recommended, rather than PSA kinetics alone. The requirement for such monitoring must be discussed with patients prior to treatment $(40,49,51-54)$. 


\section{Management after failure of focal therapy}

Following confirmed recurrence of disease, patients can be managed through surveillance, re-treatment or radical therapy. This is assessed on a case by case basis with surveillance favoured for low risk disease, re-treatment offered through the same or different energy modality depending on the location and extent of disease. Radical therapy is offered where re-treatment is not likely to succeed, is preferred by the patient or after two ablation sessions have failed to control the disease.

A recent cohort study of 82 men has shown that robot assisted radical prostatectomy after focal therapy failure is a safe procedure, with no intraoperative complications and no major postoperative complications. In this study continence recovery was good at $83 \%$ by 12 months. However, there was only $36 \%$ progression free survival after 36 months indicating an adverse disease biology in those who recur in-field following focal ablation (55). This is in keeping with findings from a systematic review showing increased risk of biochemical recurrence after salvage prostatectomy compared to primary prostatectomy (56).

A case matched comparative study by Nunes-Silva et al., revealed similar recovery of urinary continence, but lower rates of erectile function after salvage robotic radical prostatectomy, compared to primary robot assisted radical prostatectomy (57). They also concluded that the complication rates were similar and oncological outcomes also poorer compared to primary radical prostatectomy cases. It is important to note that in this study the oncological outcomes in the salvage group are inherently a different cohort to the general population of patients undergoing focal therapy, as they are pre-selected to have failed treatment. Only through a full RCT of ablation $v$ s. surgery will it become clear whether those assigned to ablation suffer an overall oncological disadvantage to those having surgery up front.

\section{Conclusions}

When patients are initially investigated using a multi parametric MRI and biopsies confirm unilateral intermediate risk disease as the dominant finding there is an alternative approach to treatment which is of strong interest to patients. The use of focal therapy should not be used to replace all whole gland treatments, or as an alternative to active surveillance, but offered to men who value functional outcome with localized clinically significant disease (58). Further with appropriate monitoring patients may be able to undergo curative whole gland treatments should they experience recurrence after focal therapy, and subsequently postpone the possible morbidity associated with such radical treatments.

Focal treatment can offer good medium-term outcomes with lower morbidity in comparison to radical therapies. Clinicians should be aware of focal treatment options and specialists have a duty to inform patients when this option exists, particularly when the evidence for radical therapy survival advantages are in danger of being overrepresented. Clinicians must allow men to decide, in the circumstances of disease suitable for focal therapy, whether they prefer the known cancer outcomes and functional consequences from established radical techniques or treatments with reduced side effects and unknown long-term comparative outcomes.

Two randomised trials have been started within the UK to address this question. The PART study pilot phase compared HIFU with radical prostatectomy in intermediate risk patients and demonstrated that the equipoise position and randomisation were possible. The main PART study (ISRCTN99760303) is partly funded by Steba biotech and is also due to open within the UK. It will be comparing radical therapy with partial ablation using photodynamic therapy which to date only has data in low risk disease. The CHRONOS study (NCT04049747) due to open in 2019 within the UK will compare the use of cryotherapy or HIFU against whole gland treatments of radical prostatectomy, radical radiotherapy or brachytherapy. The study will review the oncological and functional outcomes in patients that undergo whole gland therapy, focal therapy or focal therapy with neoadjuvant treatment in two side-byside randomized control trials. Further studies world-wide are underway reviewing focal therapy against whole gland treatment options, any conclusive results will take many years to develop. While awaiting an outcome from an RCT, clinicians must carefully counsel patients with unilateral significant disease regarding the risks/benefits of radical therapy $v s$. partial ablation and ideally encourage patients who are interested to accept the equipoise position and enter trials to answer this question.

\section{Acknowledgments}

Funding: DR is funded by Prostate Cancer UK. 


\section{Footnote}

Provenance and Peer Review: This article was commissioned by the Guest Editors (Martin J. Connor, Saiful Miah, Taimur T. Shah, Hashim U. Ahmed) for the series "Prostate Imaging and Focal Therapy" published in Translational Andrology and Urology. The article was sent for external peer review organized by the Guest Editors and the editorial office.

Conflicts of Interest: All authors have completed the ICMJE uniform disclosure form (available at http://dx.doi. org/10.21037/tau.2019.09.30). The series "Prostate Imaging and Focal Therapy" was commissioned by the editorial office without any funding or sponsorship. DR is a clinical research fellow funded by a research grant from Prostate Cancer UK. The other authors have no other conflicts of interest to declare.

Ethical Statement: The authors are accountable for all aspects of the work in ensuring that questions related to the accuracy or integrity of any part of the work are appropriately investigated and resolved.

Open Access Statement: This is an Open Access article distributed in accordance with the Creative Commons Attribution-NonCommercial-NoDerivs 4.0 International License (CC BY-NC-ND 4.0), which permits the noncommercial replication and distribution of the article with the strict proviso that no changes or edits are made and the original work is properly cited (including links to both the formal publication through the relevant DOI and the license). See: https://creativecommons.org/licenses/by-nc-nd/4.0/.

\section{References}

1. Nassiri N, Chang E, Lieu P, et al. Focal Therapy Eligibility Determined by Magnetic Resonance Imaging/ Ultrasound Fusion Biopsy. J Urol 2018;199:453-8.

2. Wilt TJ, Jones KM, Barry MJ, et al. Follow-up of Prostatectomy versus Observation for Early Prostate Cancer. N Engl J Med 2017;377:132-42.

3. Wilt TJ, Brawer MK, Jones KM, et al. Radical Prostatectomy versus Observation for Localized Prostate Cancer. N Engl J Med 2012;367:203-13.

4. Hamdy FC, Donovan JL, Lane JA, et al. 10-Year Outcomes after Monitoring, Surgery, or Radiotherapy for Localized Prostate Cancer. N Engl J Med
2016;375:1415-24.

5. Demirel CH, Altok M, Davis JW. Focal therapy for localized prostate cancer: is there a "middle ground" between active surveillance and definitive treatment? Asian J Androl 2018;21:37-44.

6. Veronesi U, Cascinelli N, Mariani L, et al. Twenty-Year Follow-up of a Randomized Study Comparing BreastConserving Surgery with Radical Mastectomy for Early Breast Cancer. N Engl J Med 2002;347:1227-32.

7. Pierorazio PM, Johnson MH, Patel HD, et al. Management of Renal Masses and Localized Renal Cancer: Systematic Review and Meta-Analysis. J Urol 2016;196:989-99.

8. Lepor H, Gold S, Wysock J. Focal Ablation of Prostate Cancer. Rev Urol 2018;20:145-7.

9. Chen K, Tay KJ, Law YM, et al. Outcomes of combination MRI-targeted and transperineal template biopsy in restaging low-risk prostate cancer for active surveillance. Asian J Urol 2018;5:184-93.

10. Voss J, Pal R, Ahmed S, et al. Utility of early transperineal template-guided prostate biopsy for risk stratification in men undergoing active surveillance for prostate cancer. BJU Int 2018;121:863-70.

11. Ahmed HU, El-Shater Bosaily A, Brown LC, et al. Diagnostic accuracy of multi-parametric MRI and TRUS biopsy in prostate cancer (PROMIS): A pair validating confirmatory study. Lancet 2017;389:815-22.

12. Simmons LAM, Kanthabalan A, Arya M, et al. The PICTURE study: diagnostic accuracy of multiparametric MRI in men requiring a repeat prostate biopsy. $\mathrm{Br} \mathrm{J}$ Cancer 2017;116:1159-65.

13. Kasivisvanathan V, Rannikko AS, Borghi M, et al. MRITargeted or Standard Biopsy for Prostate-Cancer Diagnosis. N Engl J Med 2018;378:1767-77.

14. Ahmed HU, Dickinson L, Charman S, et al. Focal Ablation Targeted to the Index Lesion in Multifocal Localised Prostate Cancer: a Prospective Development Study. Eur Urol 2015;68:927-36.

15. Choi YH, Yu JW, Jeong BC et al. Histological characteristics of the largest and secondary tumors in radical prostatectomy specimens and implications for focal therapy. Diagn Pathol 2019;14:2.

16. Mathew MS, Oto A. MRI-guided focal therapy of prostate cancer. Future Oncol 2017;13:537-49.

17. Le Nobin J, Rosenkrantz AB, Villers A, et al. Image Guided Focal Therapy for Magnetic Resonance Imaging Visible Prostate Cancer: Defining a 
3-Dimensional Treatment Margin Based on Magnetic Resonance Imaging Histology Co-Registration Analysis. J Urol 2015;194:364-70.

18. Yan $W, Z$ hou $Y, Z$ hou Z, et al. Padeliporfin vasculartargeted photodynamic therapy versus active surveillance in men with low-risk prostate cancer. Lancet Oncol 2017;18:e187.

19. Johnson DC, Yang JJ, Kwan L, et al. Do contemporary imaging and biopsy techniques reliably identify unilateral prostate cancer? Implications for hemiablation patient selection. Cancer 2019;125:2955-64.

20. McClure TD, Margolis DJ, Hu JC. Partial Gland Ablation in the Management of Prostate Cancer: a review. Curr Opin Urol 2017;27:156-60.

21. Kuru TH, van Essen J, Pfister D, et al. Role of Focal Therapy with High-Intensity Focused Ultrasound in the Management of Clinically Localized Prostate Cancer. Oncol Res Treat 2015;38:634-8.

22. Mortezavi A, Krauter J, Gu A, et al. Extensive Histological Sampling following Focal Therapy of Clinically Significant Prostate Cancer with High Intensity Focused Ultrasound. J Urol 2019;202:717-24.

23. Guillaumier S, Peters M, Arya M, et al. A Multicentre Study of 5-year Outcomes Following Focal Therapy in Treating Clinically Significant Nonmetastatic Prostate Cancer. Eur Urol 2018;74:422-9.

24. Albisinni S, Aoun F, Bellucci S, et al. Comparing HighIntensity Focal Ultrasound Hemiablation to Robotic Radical Prostatectomy in the Management of Unilateral Prostate Cancer: A Matched-Pair Analysis. J Endourol 2017;31:14-9.

25. Dickinson L, Ahmed HU, Kirkham AP, et al. A multicentre prospective development study evaluating focal therapy using high intensity focused ultrasound for localised prostate cancer: The INDEX study. Contemp Clin Trials 2013;36:68-80.

26. Bozzini G, Colin P, Nevoux P, et al. Focal therapy of prostate cancer: energies and procedures. Urol Oncol 2013;31:155-67.

27. Valerio M, Shah TT, Shah P, et al. Magnetic resonance imaging-transrectal ultrasound fusion focal cryotherapy of the prostate: A prospective development study. Urol Oncol 2017;35:150.e1-150.e7.

28. Shah TT, Peters M, Eldred-Evans D, et al. EarlyMedium-Term Outcomes of Primary Focal Cryotherapy to Treat Nonmetastatic Clinically Significant Prostate Cancer from a Prospective Multicentre Registry. Eur Urol 2019;76:98-105.
29. Bertacchini C, Margotti PM, Bergamini E, et al. Design of an Irreversible Electroporation System for Clinical Use. Technol Cancer Res Treat 2007;6:313-20.

30. Guenther E, Klein N, Zapf S, et al. Prostate cancer treatment with Irreversible Electroporation (IRE): Safety, efficacy and clinical experience in 471 treatments. PLoS One 2019; 14:e0215093.

31. van den Bos $W$, Scheltema MJ, Siriwardana AR, et al. Focal irreversible electroporation as primary treatment for localized prostate cancer. BJU Int 2018;121:716-24.

32. Scheltema MJ, Chang JI, Böhm M, et al. Pair-matched patient-reported quality of life and early oncological control following focal irreversible electroporation versus robot-assisted radical prostatectomy. World J Urol 2018;36:1383-9.

33. van den Bos $W$, de Bruin DM, Jurhill RR, et al. The correlation between the electrode configuration and histopathology of irreversible electroporation ablations in prostate cancer patients. World J Urol 2016;34:657-64.

34. Ting F, Tran M, Böhm M, et al. Focal irreversible electroporation for prostate cancer: functional outcomes and short-term oncological control. Prostate Cancer Prostatic Dis 2016;19:46-52.

35. Scheltema MJV, van den Bos W, de Bruin DM, et al. Focal vs. extended ablation in localized prostate cancer with irreversible electroporation; a multi-center randomized controlled trial. BMC Cancer 2016;16:299.

36. Lee T, Mendhiratta N, Sperling D, et al. Focal laser ablation for localized prostate cancer: principles, clinical trials, and our initial experience. Rev Urol 2014;16:55-66.

37. Natarajan S, Jones TA, Priester AM, et al. Focal Laser Ablation of Prostate Cancer: Feasibility of Magnetic Resonance Imaging-Ultrasound Fusion for Guidance. J Urol 2017;198:839-47.

38. Lindner U, Lawrentschuk N, Weersink RA, et al. Focal Laser Ablation for Prostate Cancer Followed by Radical Prostatectomy: Validation of Focal Therapy and Imaging Accuracy. Eur Urol 2010;57:1111-4.

39. Lepor H, Llukani E, Sperling D, et al. Complications, Recovery, and Early Functional Outcomes and Oncologic Control Following In-bore Focal Laser Ablation of Prostate Cancer. Eur Urol 2015;68:924-6.

40. Valerio M, Cerantola Y, Eggener SE, et al New and Established Technology in Focal Ablation of the Prostate: A Systematic Review. Eur Urol 2017;71:17-34.

41. Zlotta AR, Djavan B, Matos C, et al. Percutaneous transperineal radiofrequency ablation of prostate tumour: safety, feasibility and pathological effects on human 
prostate cancer. Br J Urol 1998;81:265-75.

42. Laing R, Franklin A, Uribe J, et al. Hemi-gland focal low dose rate prostate brachytherapy: An analysis of dosimetric outcomes. Radiother Oncol 2016;121:310-5.

43. Fernandez Ots A, Bucci J, Chin YS, et al. Hemiablative Focal Low Dose Rate Brachytherapy: A Phase II Trial Protocol. JMIR Res Protoc 2016;5:e98.

44. Peters M, van Son MJ, Moerland MA, et al. MRI-Guided Ultrafocal HDR Brachytherapy for Localized Prostate Cancer: Median 4-Year Results of a feasibility study. Int J Radiat Oncol Biol Phys 2019;104:1045-53.

45. Apfelbeck M, Clevert DA, Ricke J, et al. Contrast enhanced ultrasound (CEUS) with MRI image fusion for monitoring focal therapy of prostate cancer with high intensity focused ultrasound (HIFU)1. Clin Hemorheol Microcirc 2018;69:93-100.

46. Chaussy CG, Thüroff S. High-Intensity Focused Ultrasound for the Treatment of Prostate Cancer: A Review. J Endourol 2017;31:S30-7.

47. Polascik TJ, Mayes JM, Schroeck FR, et al. Patient selection for hemiablative focal therapy of prostate cancer. Cancer 2009; 115:2104-10.

48. Tay KJ, Scheltema MJ, Ahmed HU, et al. Patient selection for prostate focal therapy in the era of active surveillance: an International Delphi Consensus Project. Prostate Cancer Prostatic Dis 2017;20:294-9.

49. Tay KJ, Amin MB, Ghai S, et al. Surveillance after prostate focal therapy. World J Urol 2019;37:397-407.

50. Edison E, Tariq Shah T, Ahmed HU. Focal Ablation of Early-Stage Prostate Cancer. Urol Clin North Am 2017;44:575-85.

51. Albisinni S, Mélot C, Aoun F, et al. Focal Treatment for

Cite this article as: Reddy D, Bedi N, Dudderidge T. Focal therapy, time to join the multi-disciplinary team discussion? Transl Androl Urol 2020;9(3):1526-1534. doi:10.21037/ tau.2019.09.30
Unilateral Prostate Cancer Using High-Intensity Focal Ultrasound: A Comprehensive Study of Pooled Data. J Endourol 2018;32:797-804.

52. Ganzer R, Hadaschik B, Pahernik S, et al. Prospective Multicenter Phase II Study on Focal Therapy (Hemiablation) of the Prostate with High Intensity Focused Ultrasound. J Urol 2018;199:983-9.

53. Postema AW, De Reijke TM, Ukimura O, et al. Standardization of definitions in focal therapy of prostate cancer: report from a Delphi consensus project. World J Urol 2016;34:1373-82.

54. Felker ER, Raman SS, Lu DSK, et al. Utility of Multiparametric MRI for Predicting Residual Clinically Significant Prostate Cancer After Focal Laser Ablation. AJR Am J Roentgenol 2019. doi: 10.2214/AJR.19.21637.

55. Marconi L, Stonier T, Tourinho-Barbosa R, et al. Robotassisted Radical Prostatectomy After Focal Therapy: Oncological, Functional Outcomes and Predictors of Recurrence. Eur Urol 2019;76:27-30.

56. Marra G, Gontero P, Walz JC, et al. Complications, oncological and functional outcomes of salvage treatment options following focal therapy for localized prostate cancer: a systematic review and a comprehensive narrative review. World J Urol 2019;37:1517-34.

57. Nunes-Silva I, Barret E, Srougi V, et al. Effect of Prior Focal Therapy on Perioperative, Oncologic and Functional Outcomes of Salvage Robotic Assisted Radical Prostatectomy. J Urol 2017;198:1069-76.

58. Kluytmans A, Fütterer JJ, Emberton M, et al. Exploring the risk-reward balance in focal therapy for prostate cancer-a contribution to the debate. Prostate Cancer Prostatic Dis 2019;22:382-4. 
Table S1 Trials and studies currently registered with clinicaltrials.gov and recruiting

\begin{tabular}{|c|c|c|c|c|c|}
\hline Trial/study name & Country/region & Study type & Intervention & Primary outcome measure & $\begin{array}{l}\text { Clinicaltrials.gov } \\
\text { identifier }\end{array}$ \\
\hline $\begin{array}{l}\text { Comparative health research outcomes of novel surgery in } \\
\text { prostate cancer }\end{array}$ & UK & $\begin{array}{l}\text { Phase II/III } \\
\text { interventional trial }\end{array}$ & HIFU or cryotherapy & $\begin{array}{l}\text { Progression and failure free } \\
\text { survival }\end{array}$ & NCT04049747 \\
\hline $\begin{array}{l}\text { Multi-center randomized clinical trial irreversible } \\
\text { electroporation for the ablation of localized prostate cancer }\end{array}$ & The Netherlands & $\begin{array}{l}\text { Phase II } \\
\text { interventional trial }\end{array}$ & IRE & Functional outcomes & NCT01835977 \\
\hline $\begin{array}{l}\text { CyberKnife }{ }^{\circledR} \text { as monotherapy or boost SBRT for intermediate } \\
\text { or high risk localized prostate cancer }\end{array}$ & USA & Interventional & $\begin{array}{l}\text { Cyberknife } \\
\text { vs. ADT +/- IMRT }\end{array}$ & bDFS & NCT01985828 \\
\hline Outcomes of focal therapies for prostate cancer & USA & Observational & $\begin{array}{l}\text { Focal of multiple } \\
\text { methods }\end{array}$ & Post-treatment biopsy histology & NCT03492424 \\
\hline Phase II laser focal therapy of prostate cancer (LITT or FLA) & USA & $\begin{array}{l}\text { Phase II, } \\
\text { observational }\end{array}$ & $\begin{array}{l}\text { MR-guided laser focal } \\
\text { therapy }\end{array}$ & Safety and adverse events & NCT02243033 \\
\hline $\begin{array}{l}\text { Intervention trial evaluating focal therapy using high intensity } \\
\text { focused ultrasound for the treatment of prostate cancer }\end{array}$ & Switzerland & Phase II/III & Focal HIFU & $\begin{array}{l}\text { Oncological safety-clinically } \\
\text { significant prostate cancer free } \\
\text { survival }\end{array}$ & NCT02265159 \\
\hline Focal therapy for prostate cancer using HIFU (INDEX) & UK & Interventional & Focal HIFU & $\begin{array}{l}\text { Conversion to radical therapy and/ } \\
\text { or requiring systemic therapy and/ } \\
\text { or developing metastases and/or } \\
\text { dying of prostate cancer }\end{array}$ & NCT01194648 \\
\hline $\begin{array}{l}\text { Examination of focal therapies-MRI-Fusion, HIFU, NanoKnife } \\
\text { and Cryotherapy }\end{array}$ & Israel & Observational & $\begin{array}{l}\text { Focal HIFU, NanoKnife, } \\
\text { cryotherapy }\end{array}$ & $\begin{array}{l}\text { Prostate cancer detection rate } \\
\text { and clinically significant prostate } \\
\text { cancer detection rate of MRI-US } \\
\text { FUSION biopsy } \\
\text { PSA change after focal therapy }\end{array}$ & NCT03982706 \\
\hline High-intensity focused ultrasound study & Hong Kong & Interventional & Focal HIFU & $\begin{array}{l}\text { Absence of prostate cancer on } \\
\text { biopsy }\end{array}$ & NCT03927924 \\
\hline $\begin{array}{l}\text { Prospective evaluation of focal brachytherapy using } \\
\text { cesium- } 131 \text { for patients with low risk prostate cancer }\end{array}$ & USA & $\begin{array}{l}\text { Interventional } \\
\text { phase II }\end{array}$ & Focal brachytherapy & Biochemical disease free survival & NCT02290366 \\
\hline $\begin{array}{l}\text { Efficacy evaluation of focused HIFU therapy in patients with } \\
\text { localized intermediate risk prostate cancer (FOCALE) }\end{array}$ & France & $\begin{array}{l}\text { Interventional } \\
\text { phase II }\end{array}$ & Focal HIFU & $\begin{array}{l}\text { The patient proportion with con- } \\
\text { trolled disease }\end{array}$ & NCT03568188 \\
\hline $\begin{array}{l}\text { HIFU for focal ablation of prostate tissue: an observational } \\
\text { study }\end{array}$ & USA & Observational & Focal HIFU & Oncological response & NCT03620786 \\
\hline $\begin{array}{l}\text { The composite steep-pulse treatment apparatus used in } \\
\text { prostate cancer ablation therapy }\end{array}$ & China & Interventional & Steep pulse device & $\begin{array}{l}\text { Survival from clinically significant } \\
\text { prostate cancer }\end{array}$ & NCT03838432 \\
\hline $\begin{array}{l}\text { Prospective clinical safety and efficacy study of } \\
\text { lesion-targeted MRI-TULSA for localized prostate cancer } \\
\text { (PRO-TULSA-PC) }\end{array}$ & Finland & Interventional & MRI-TULSA & $\begin{array}{l}\text { Disease free survival; severe } \\
\text { adverse event free survival }\end{array}$ & NCT03814252 \\
\hline $\begin{array}{l}\text { Phase } 3 \text {, multicenter, randomized study, evaluating the } \\
\text { efficacy and tolerability of focused HIFU therapy compared } \\
\text { to active surveillance in patients with significant low risk } \\
\text { prostate cancer (HIFUSA) }\end{array}$ & France & $\begin{array}{l}\text { Interventional } \\
\text { phase III }\end{array}$ & Focal HIFU & $\begin{array}{l}\text { The patient proportion who } \\
\text { needed to seek radical treatment }\end{array}$ & NCT03531099 \\
\hline MRI Guided focal laser ablation of prostate cancer (MRgFLA) & Canada & Interventional & $\begin{array}{l}\text { MRI guided focal laser } \\
\text { ablation }\end{array}$ & $\begin{array}{l}\text { The proportion of study patients } \\
\text { clinically free of clinically } \\
\text { significant PCa }\end{array}$ & NCT03650595 \\
\hline Focal prostate ablation versus radical prostatectomy (FARP) & Norway & $\begin{array}{l}\text { Interventional, } \\
\text { comparative }\end{array}$ & $\begin{array}{l}\text { Focal HIFU vs. } \\
\text { radical robot assisted } \\
\text { prostatectomy }\end{array}$ & Treatment failure & NCT03668652 \\
\hline $\begin{array}{l}\text { Focal ExAblate MR-guided focused ultrasound treatment for } \\
\text { management of organ-confined intermediate risk prostate } \\
\text { cancer }\end{array}$ & Canada & Interventional & $\begin{array}{l}\text { Exablate MR guided } \\
\text { Focussed Ultrasound }\end{array}$ & $\begin{array}{l}\text { Presence of clinically significant } \\
\text { prostate cancer }\end{array}$ & NCT02968784 \\
\hline Hemiablative focal brachytherapy pilot study & Australia & $\begin{array}{l}\text { Interventional } \\
\text { phase II }\end{array}$ & $\begin{array}{l}\text { Hemiablative } \\
\text { brachytherapy }\end{array}$ & Optimal dosimetry & NCT02643511 \\
\hline Focal laser ablation of prostate cancer tumours & USA & Interventional & Focal laser ablation & $\begin{array}{l}\text { Procedural success rate; rate of } \\
\text { adverse events }\end{array}$ & NCT02600156 \\
\hline $\begin{array}{l}\text { Focused stereotactic radiation treatment of prostatic adeno- } \\
\text { carcinoma }\end{array}$ & Luxembourg & Observational & Cyberknife & Time to salvage treatment & NCT03284151 \\
\hline Fusion guided focal laser ablation of prostate cancer & USA & $\begin{array}{l}\text { Interventional } \\
\text { phase III }\end{array}$ & $\begin{array}{l}\text { Ultrasound image } \\
\text { guided focal ablation- } \\
\text { laser or cryotherapy }\end{array}$ & Feasibility of method & NCT02759744 \\
\hline $\begin{array}{l}\text { MRI guided transurethral HIFU for various prostate diseases } \\
\text { (HIFU-PRO) }\end{array}$ & Finland & $\begin{array}{l}\text { Interventional } \\
\text { phase I }\end{array}$ & Focal HIFU & $\begin{array}{l}\text { Evaluating treatment accuracy } \\
\text { Safety profile }\end{array}$ & NCT03350529 \\
\hline $\begin{array}{l}\text { Efficacy and safety assessment of IRE of localized prostate } \\
\text { cancer }\end{array}$ & Russia & Interventional & $\begin{array}{l}\text { Nanoknofe } \\
\text { focal irreversible } \\
\text { electroporation }\end{array}$ & PSA post procedure; safety profile & NCT03504995 \\
\hline $\begin{array}{l}\text { Focal brachytherapy in patients with selected "Low-risk" } \\
\text { prostate cancer-a phase-II-trial (FOKAL-BT) }\end{array}$ & Germany & $\begin{array}{l}\text { Interventional } \\
\text { phase II }\end{array}$ & Focal brachytherapy & $\begin{array}{l}\text { Intensity and frequency of adverse } \\
\text { events }\end{array}$ & NCT02391051 \\
\hline
\end{tabular}

HIFU, high intensity focused ultrasound; IRE, irreversible electroporation; LITT, laser interstitial thermotherapy; FLA, focal laser ablation; ADT, androgen-deprivation therapy; IMRT, intensity-modulated radiation therapy; bDFS, biochemical disease-free survival. 